\title{
Ankle joint synoviography in rheumatoid arthritis
}

\author{
G. HUG AND A. ST. J. DIXON
}

From the Royal National Hospital for Rheumatic Diseases, Upper Borough Walls, Bath BAI IRL

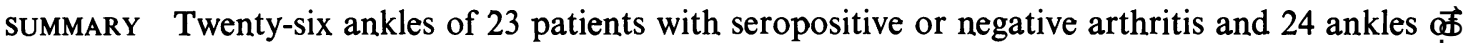
12 cadavers as a control group were studied by contrast synoviography. The main features in the patients were capsule enlargement, hypertrophic synovitis, and connections to tendon sheaths and to the posterior subtalar joint. None of the controls showed capsule distension or irregular outline of the joint cavity, but connections to tendon sheaths and /or to the posterior subtalar joint were present. Other features such as tibiofibular recess, early lymphatic filling, and joint destruction were seeß

Contrast synoviography is a skill essential to the rheumatologist. It can show the size and form of the synovial cavity, the thickness and integrity of the cartilage, the presence of intra-articular loose bodies, tumours, or villous structures, connections with cysts, bursae, and tendon sheaths (Gerber and Dixon, 1974; Dixon and Rasker, 1976), acute synovial rupture (Dixon and Grant, 1964), and ligamentous tears (Spiegel and Staples, 1975). Nevertheless, ankle synoviography has rarely been reported except for ligamentous injuries (Fulp, 1973; Toth et al., 1974; Harris and Galinski, 1974) and is seldom used in rheumatoid arthritis (RA). However, the ankle was clinically affected in about $50 \%$ of patients in Vidigal and colleagues' (1975) study of the rheumatoid foot, nearly twice the number who showed damage on $x$-ray. The reverse was the case with the tarsal joints (Kirkup, 1974).

Fig. 1 shows synovial and other structures at risk around the ankle. Their involvement has been confirmed at operation (Vahvanan, 1968). In hindfoot surgery, tarsal joint operations are more often necessary than those on the ankles (Vahvanan, 1967), but interest in ankle replacement is increasing (Scholz, 1974; Engelbrecht, 1975; Kempson, et al. 1975; Stauffers, 1976; Waugh et al., 1976). We have therefore studied the ankle synoviogram in normal subjects and in those with seropositive and seronegative arthritis.

\section{Subjects}

We selected 19 patients with active, classical, or definite RA (Ropes et al., 1959) and 4 with seronegative polyarthritis in whom the ankle joint

Accepted for publication March 14, 1977

Correspondence to Dr. A. St. J. Dixon caused disability. 26 synoviograms were obtaine $₫$ 24 synoviograms were performed in 12 cadavers with normal ankles.

\section{Methods}

We used the anterior approach for synoviography The joint line was found by palpation and the neegdie entered horizontally lateral to the tibialis antefior

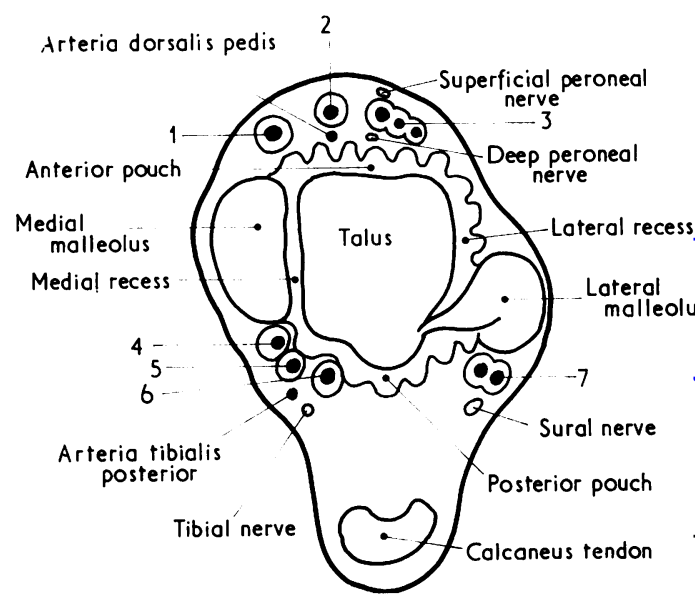

Fig. 1 Transverse section through the upper part of the talocrural joint. Viewed from above. (Modified from Gray's Anatomy, 33rd ed., 1962.)

1 Tendon and tendonsheath of tibialis anterior

2 Tendon and tendonsheath of extensor hallucis longus

3 Tendons and tendonsheaths of extensor digitorum

longus and peroneus tertius

4 Tendon and tendonsheath of tibialis posterior

5 Tendon and tendonsheath of flexor digitorum longus

6 Tendon and tendonsheath of flexor hallucis longus

7 Tendons and tendonsheaths of peronei longus et brevis 
tendon. A 5:1 mixture of contrast medium Conray 280 (meglumine iothalamate) $60 \%$ to lignocaine $1 \%$ was injected using full aseptic, 'no-touch' technique. Some patients with obvious ankle inflammation also received $1 \mathrm{ml}$ of $20 \mathrm{mg}$ triamcinolone hexacetonide (Lederspan). We found it helpful to position the needle first by assessing injection pressure using lignocaine alone, before changing to a syringe charged with the premixed contrast medium. The volume injected was varied according to the resistance and to any discomfort produced and was on average
$9.5 \mathrm{ml}$ (range 6-14 $\mathrm{ml}$ ). To avoid leakage along the needle track we found it advisable to hold the needle still for 30 seconds and then to withdraw it quickly, keeping negative pressure on the plunger and immediately applying pressure to the injection point for a few seconds. Radiographs were taken immediately after injection in standard anterposterior and lateral views, nonweight-bearing, using a GEC D55 unit with a $1 \mathrm{~mm}$ beam source and recorded on Kodak (Kodirex KD5AT) or Ilford (Ilflex 90 and Red Seal) films. The synoviograms obtained after

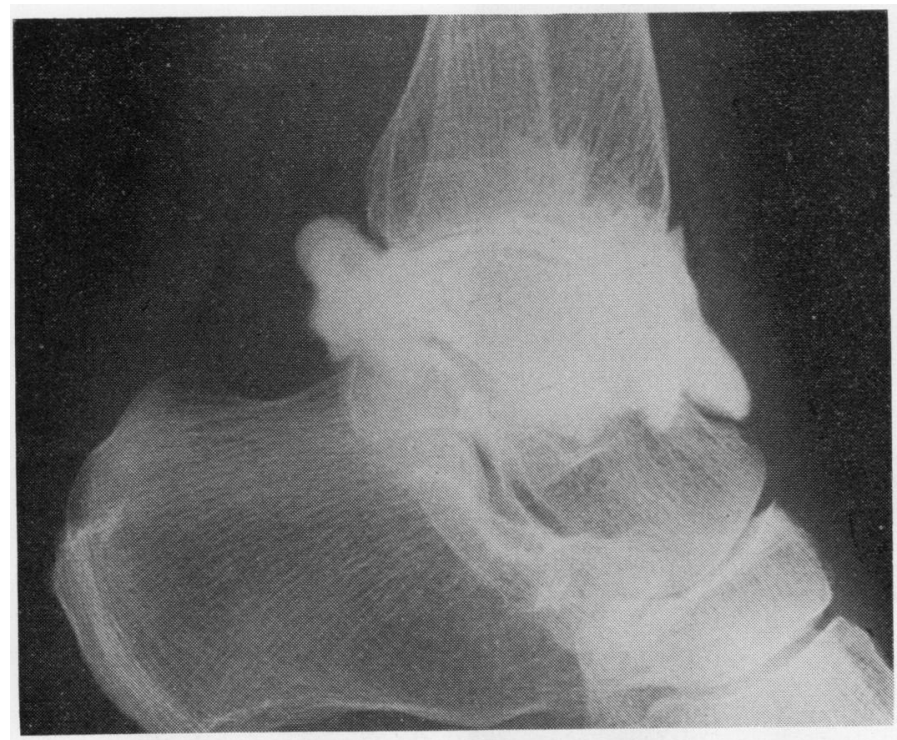

Fig. 2 Woman, aged 73, died of pulmonary embolism and coronary heart disease. Lateral view of left ankle. Normal ankle synoviogram, showing anterior and posterior capsular pouches.

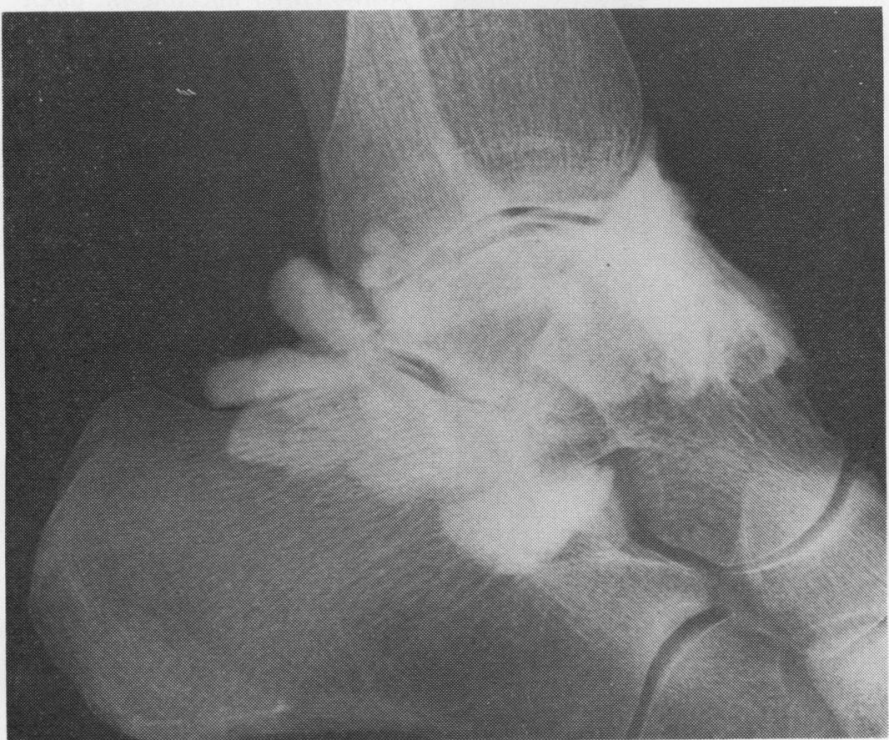

Fig. 3 Woman, aged 58, died of cancer of the colon. Lateral view of right ankle. Normal ankle synoviogram, showing connection with the posterior talocalcaneal joint. Note the separate pouches and recesses of the latter. 
weight bearing or after 7 minutes' delay gave no information which was not apparent in those taken immediately after injection and are not further reported. Contrast was injected by the same route in the cadaveric joints within 36 hours of death.

Twenty-three patients ( 26 ankles) were studied. 19 patients (21 ankles) had classical or definite rheuma toid arthritis. The four other diagnoses (5 ankles) ? were ulcerative colitis with associated arthritis, $\Rightarrow$ Reiter's disease, psoriatic arthritis, and seronegative? RA. The age and sex distribution of the subjects are shown in Table 1 . The youngest subject was a man

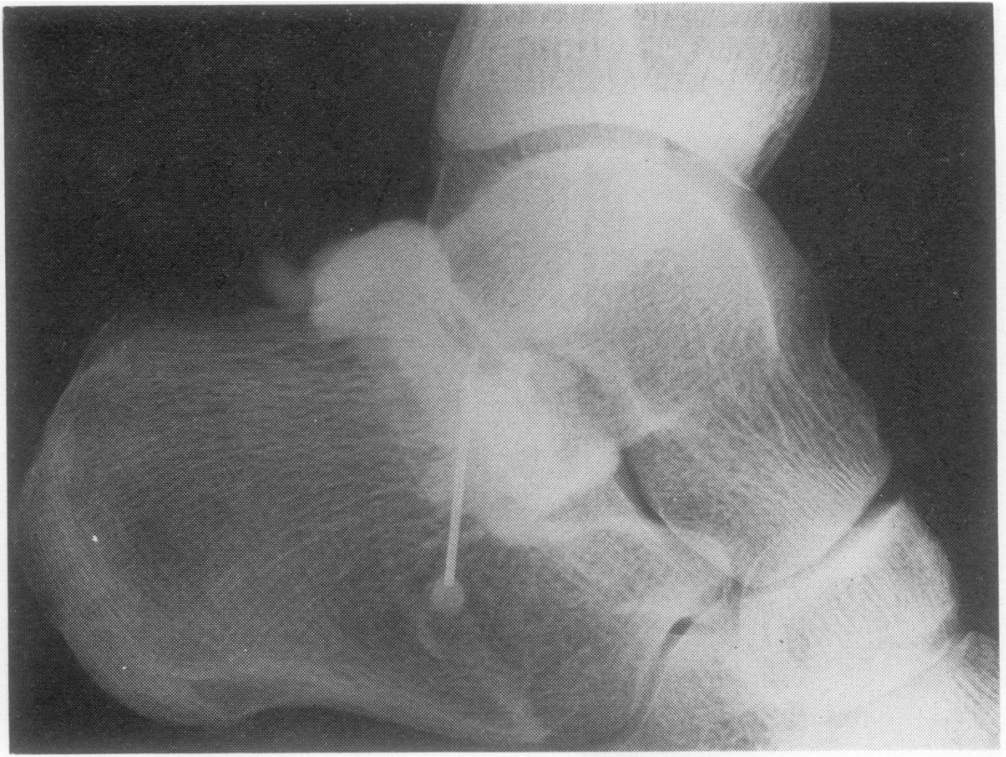

(a)

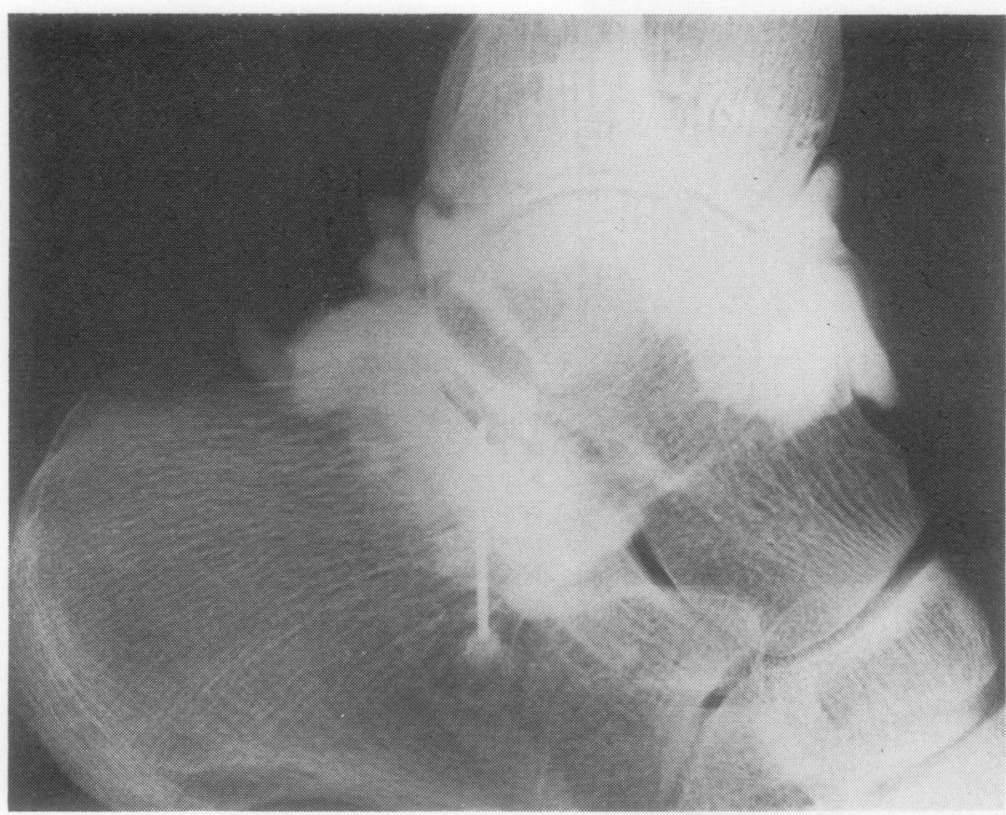

Fig. 4 Male, aged 60, died from myocardial infarction. Lateral view of right ankle.

(a) Synoviogram of a normal posterior calcaneal joint after injecting from the lateral approach. Note posterior pouch. (b) The same foot in the same position after injecting the ankle anteriorly. Note the intimate contact between the posterior pouches of the two joints. 


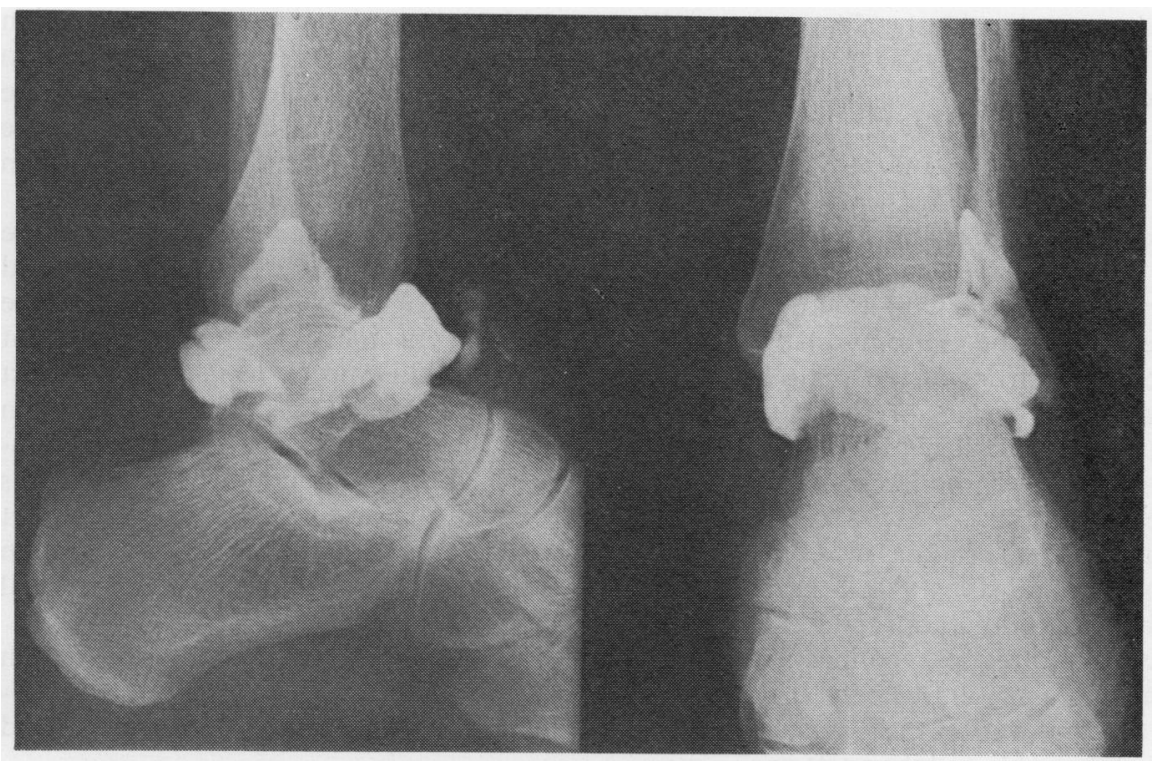

Fig. 5 Woman, aged 57, seropositive RA for 16 years. Pain and tenderness of both ankles with only moderate inflammation. Left ankle, lateral and anteroposterior views. Synovial cavity size and outline are almost normal. Five typical pouches are seen: (lateral view) anterior and posterior pouches, (AP view) medial, lateral, and tibiofibular pouches.

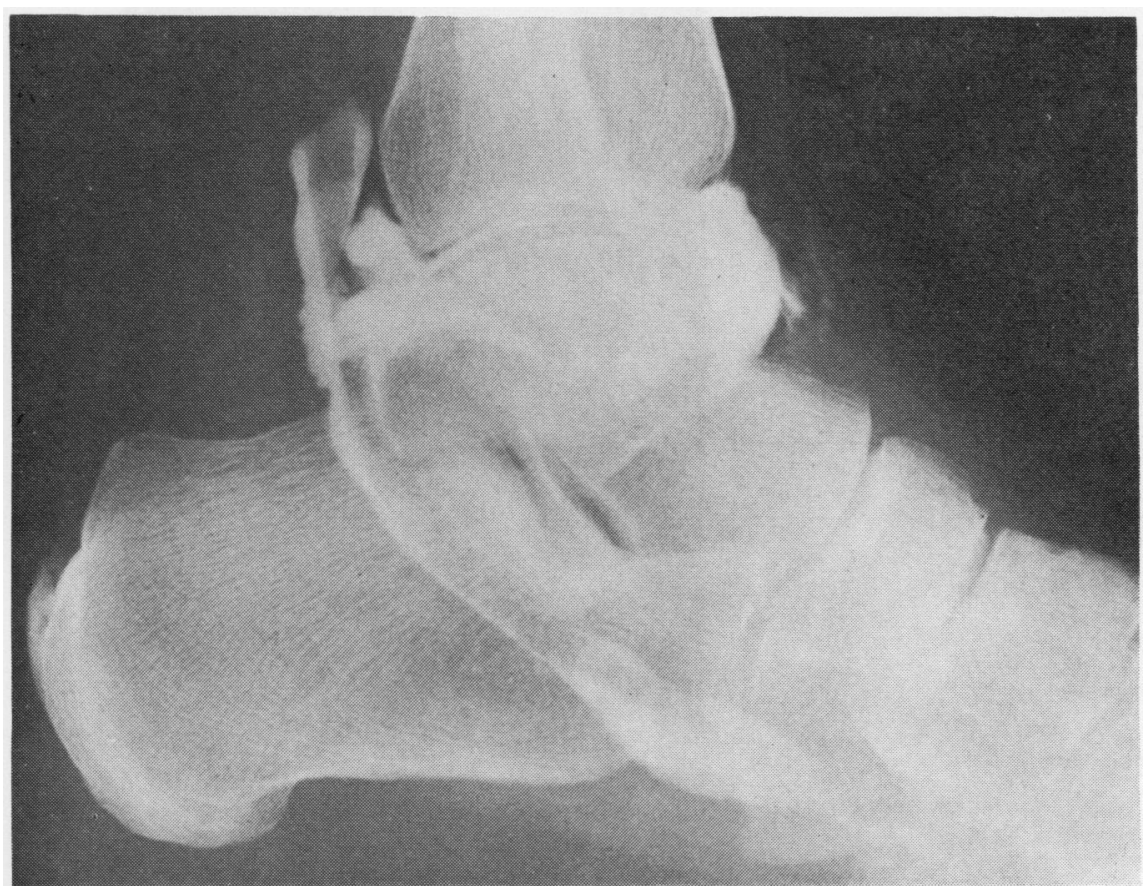

Fig. 6 Man, aged 56, seropositive RA with ankle involvement for 2 years. Right ankle, lateral view. Synoviogram shows little evidence of villous hypertrophy but the ankle connects posteriorly with the flexor hallucis longus tendon sheath. 
aged 21 with Reiter's disease, the eldest a 71-yearold woman with RA. The duration of disease varied from 6 months to 28 years.

\section{Results and discussion}

Table 2 summarizes the main findings and Figs. 2-9 give examples of the synoviographic appearance. Performing synoviography in the ankle joints requires only moderate skill. If the anatomy of the tendons and vital structures in front of the ankle is remembered and the anterior margin of the talocrural is palpated it is usually quite easy to enter the joint. With practice it becomes unnecessary to anaesthetize the joint capsule first.

Our findings on the normal cadaveric joints confirm reports (Harris and Galinski, 1974; Spiegel and Staples, 1975) of the variability in normal ankle synoviograms and the not infrequent connection with tendon sheaths and subtalar joints. Even when these joints are not in communication the posterior synovial out-pouchings of the ankle and the posterior subtalar joint are in intimate relationship (Fig. 3)

Table 1 Sex and age distribution

\begin{tabular}{lcccccccc}
\hline \multicolumn{7}{c}{ Years } & & \\
\cline { 3 - 8 } & $n$ & $21-30$ & $31-40$ & $41-50$ & $51-60$ & $61-70$ & $71-80$ & $80+$ \\
\hline $\begin{array}{l}\text { Cadaveric } \\
\text { subjects }\end{array}$ & 7 & & & & 1 & 2 & 4 & 0 \\
$\begin{array}{l}\text { Female } \\
\text { Male }\end{array}$ & 5 & & & & 1 & 1 & 1 & 2 \\
$\begin{array}{l}\text { Patients with RA } \\
\text { Female }\end{array}$ & 14 & 1 & 3 & 2 & 4 & 3 & 1 & \\
Male & 9 & 1 & 0 & 2 & 1 & 5 & 0 & \\
\hline
\end{tabular}

Table 2 Arthrographic findings in normals and rheumatoid patients

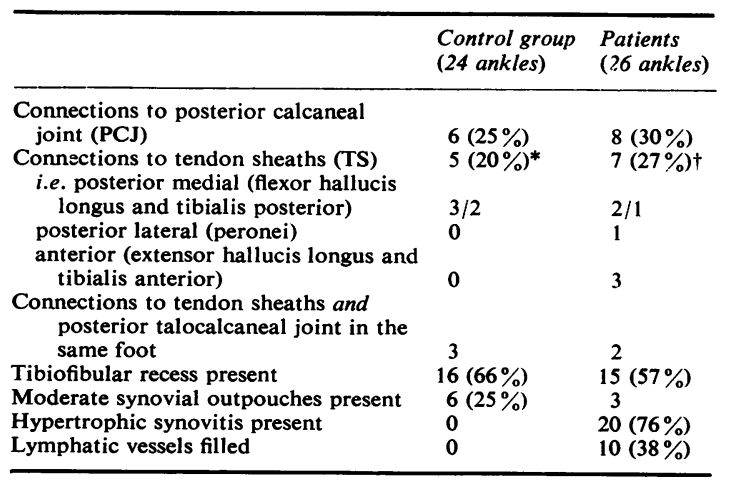

*These 11 connections (6 PCJ and 5 TS) were seen in 4 out of 12 12 subjects $(33 \%)$.

†These 15 connections ( 8 PCJ and 7 TS) were seen in 12 out of 23 patient $(56 \%)$. and presumably this is the site of the connection between the two synovial cavities which may develog in rheumatoid arthritis. In the latter disease the ankle arthrograms differed considerably from tho $\overline{\overrightarrow{\mathrm{e}}}$ of the cadaveric radiographs and they differed from each other.

The main features of the rheumatoid ankle we enlargement of the synovial cavity (Fig. 5) and marked irregularity of the synovial outline in the more inflammatory instances (Fig. 8). We have nơt seen any particular differences which could reflea general disease activity or distinguish RA from seronegative arthritis. 13 patients $(56 \%)$ had con nections between the ankle joint and tendon sheat (Figs. 6,7) or with the posterior talocalcaneal joiph (Fig. 8). This is more than in the post-mortem group (4 cadavers, $33 \%$ ) or in the other norma studies (e.g. 12\%, Fulp, 1973).

Leaks into the peroneal tendon sheaths have beep described as compatible with tears of the fibulor calcaneal ligament (Sanders, 1973; Harris and

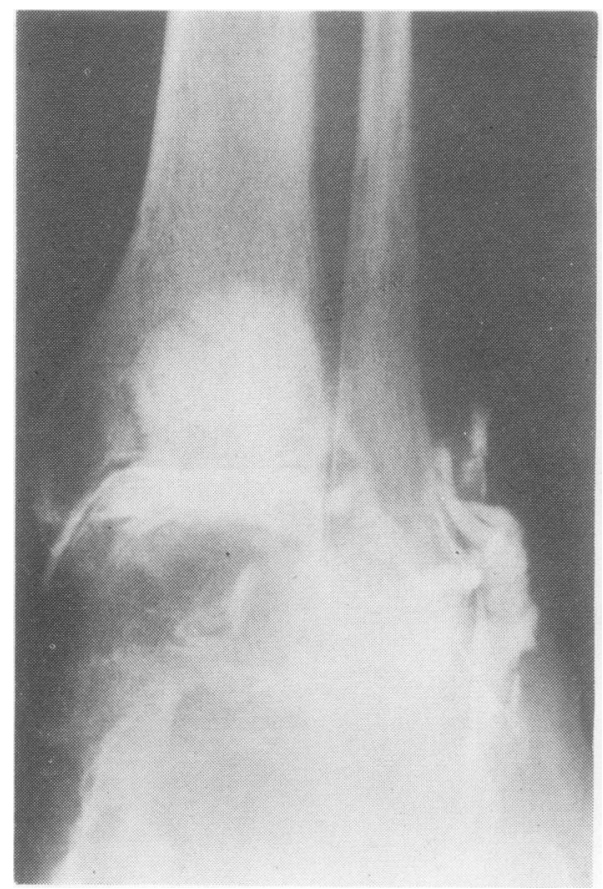

Fig. 7 Man, aged 65, severe seropositive $R A$ for 16 years. Grotesque valgus deformity of both feet; disease activity only slight. Left ankle, AP view. The synoviogram shows a thin, medial recess, cartilage irregulartities in the medial talocrural joint, a connection with the peroneal tendon sheath on the laterat aspect of the ankle, and a lateral connection with the posterior talocalcaneal joint. 


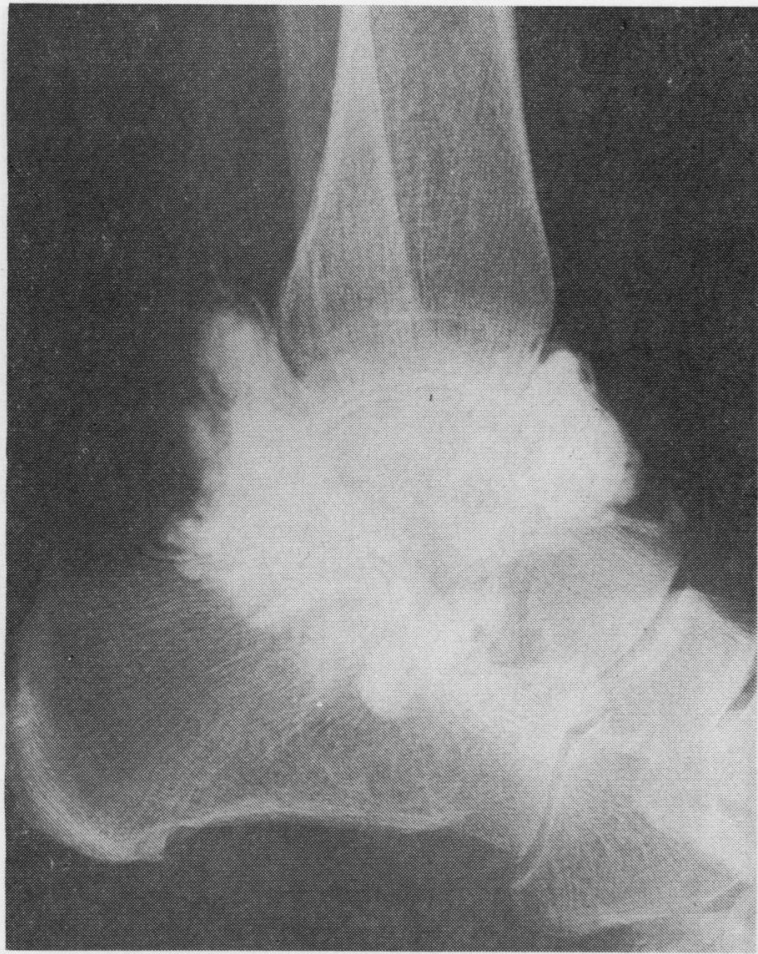

Fig. 8 Woman, aged 58, seropositive $R A$ for 5 years with involvement of the feet for 4 years; moderate inflammation of the ankle. Left ankle lateral and AP views. Marked villous synovial hypertrophy together with connections with the posterior talocalcaneal joint. Lymphatics filled posteriorly. Enlarged anterior, posterior, lateral, and medial pouches.

Galinski, 1974; Spiegel and Staples, 1975). The collateral ligaments of the rheumatoid foot, when they are exposed at operation often show ligamentous involvement and tears in the lateral group of ligaments (Vahvanan, 1967). A prolonged tibiofibular recess may indicate a rupture of the distal tibiofibular synostosis (Fulp, 1973) and this is important because routine radiographic techniques are inadequate for diagnosing an injury of this type to the ankle mortice. 15 ankles (57\%) in the patient group showed a tibiofibular recess. 3 of these were of considerable size but had not shown diastasis on routine radiographs.

It is unusual to see outlining of the lymphatic vessels in normal ankle synoviography $(2 \%$ in 233 synoviograms studied by Reinhardt (1973)). In our own series 10 ankles (38\%) showed contrast material entering the lymphatic (Fig. 9). Significant pooling in lymphatic drainage in rheumatoid arthritis has been described (Jayson et al., 1971). Either this or the

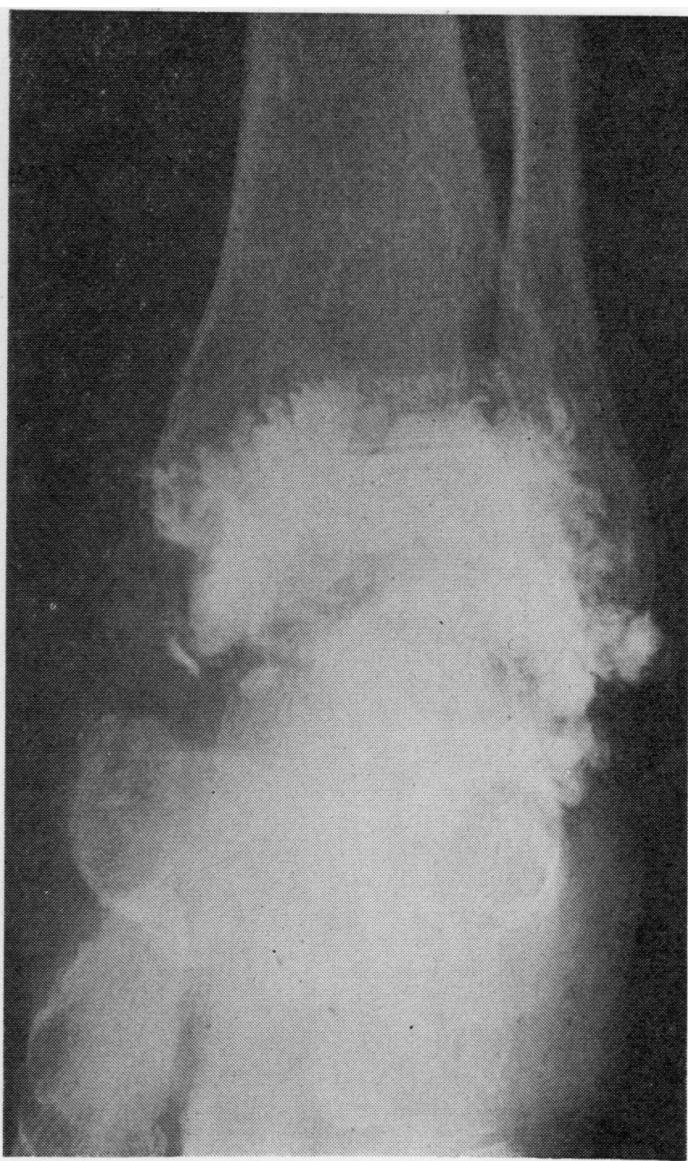

considerably increased permeability of the rheumatoid synovium may be the cause of this rapid lymphatic filling in rheumatoid arthritis. It appears to show a good relationship with synovial hypertrophy as judged by the synoviogram.

Although the ankle appeared to be affected in all 23 patients, 6 of them had normal arthrograms without evidence of hypertrophic synovitis or capsular distension. In 5 of these the ankle communicated with other synovial structures, suggesting a protective value of such connections similar to that shown for the knee by Genovese et al. (1972).

Swelling and oedema of the ankle region was very common in our patients. Simple enlargement of the ankle joint was never the only cause of the swollen ankle. Large synovial cysts and chronic synovitis of the knee with subsequent obstruction of veins and probably of the lymphatic vessels, lymphadenopathy (Kalliomaeki and Vastamaeki, 1968), profuse inflammatory exudate around the joint, and possibly 


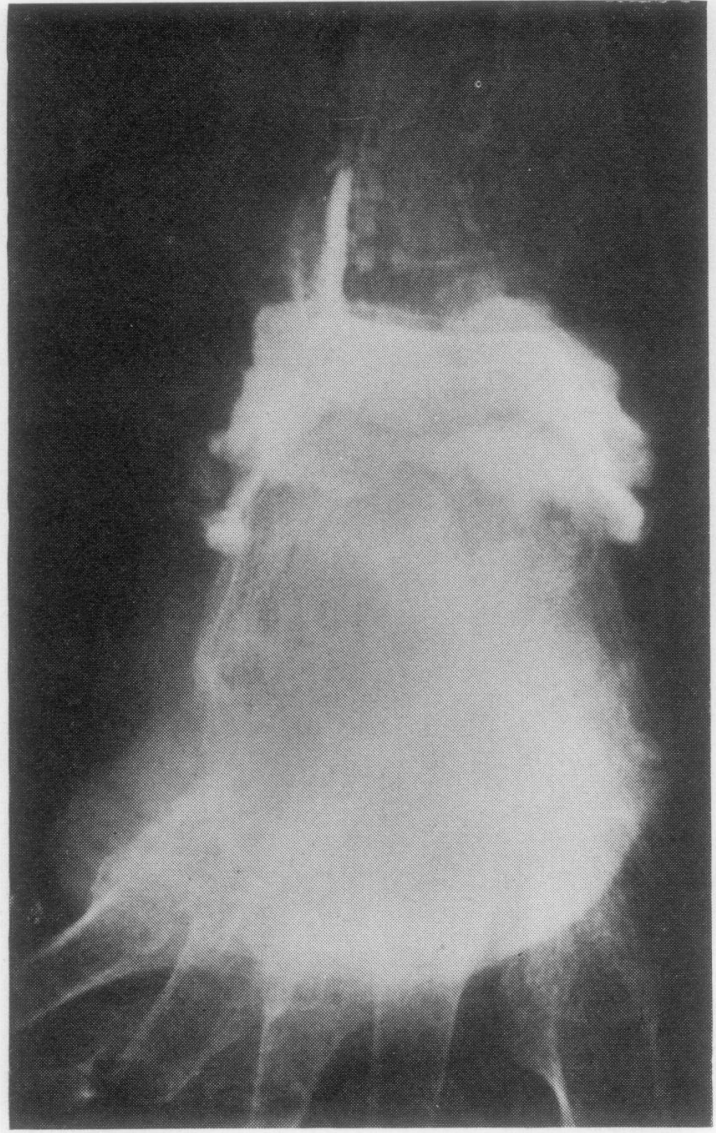

a destructive metabolism of the interstitial fibrous tissue due to corticosteroid therapy have been considered as likely mechanisms for the rheumatoid oedema (Dixon, 1971). In this series we did not see any large extra-articular cysts or interosseous geodes connecting with the ankle joint.

It is clearly important to know as much as possible about the ankle joint when any form of local therapy is contemplated. The use of intrasynovial long-acting corticosteroids such as triamcinolone hexacetonide is becoming increasingly popular as early fears about the damage that this may inflict on the articular cartilage are seen to be unfounded. Nevertheless, the results are variable and clearly a single injection which can penetrate to many synovial structures around the ankle joint because of synovial communication is likely to be more effective than one which picks off only one of the potentially diseased structures. Surgeons contemplating synovectomy around the ankle will also clearly need to know the anatomical connections. For example, a synovectomy of the posterior tibial tendon sheath is unlikely to be beneficial if this is swollen because of

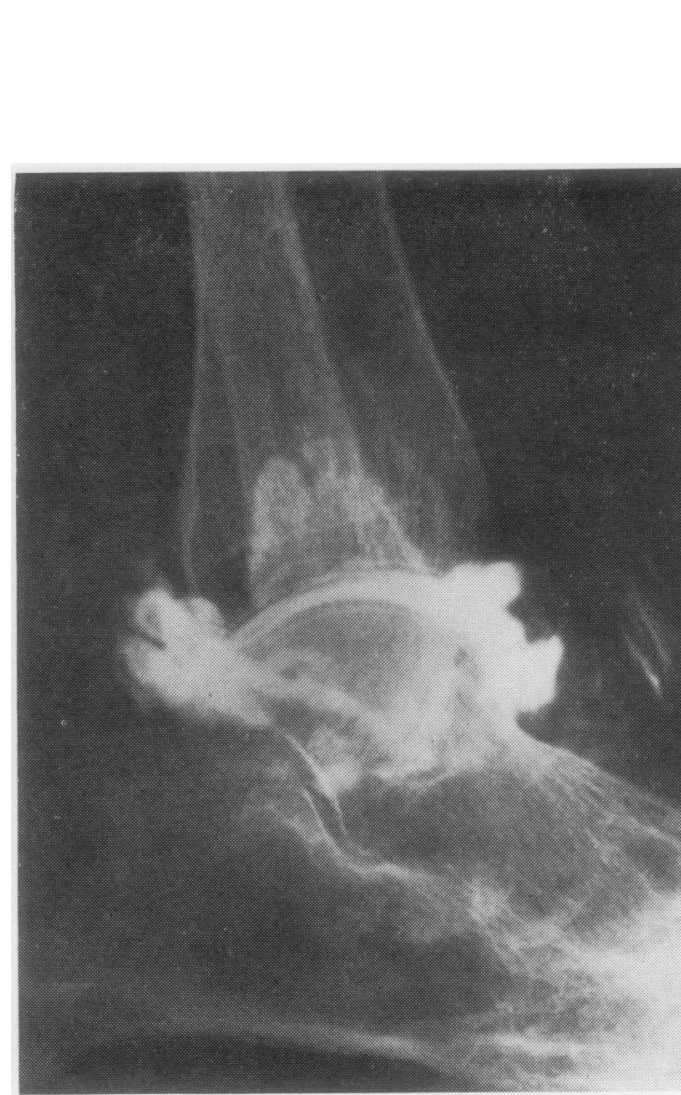

Fig. 9 Woman, aged 57, severe seropositive $R A$ for 10 years; unable to walk because of foot pain. Right ankle, AP and lateral views. Villous synovitis, marked lymphatic filling and opacification of i small lymph node. Marked tibiofibular recess. Note spontaneous fusion of the midtarsal and anterior subtalar joints.

a connection with a swollen ankle. Synoviography can also give useful information to the surgeon contemplating total joint replacement arthroplasty. which will inevitably depend on the integrity of the lower tibiofibular synostosis.

We thank Drs. J. A. Cosh and P. Bacon for allowing us to examine their patients; Drs. R. L. Bishton and J. V. Lever from the pathology service, Roya? United Hospital, Bath, for allowing us to studo cadavers; Mr. N. L. Gay, superintendent radio grapher, and Miss S. Sawyer, radiographer, folos helping to take $x$-rays in the mortuaries at the Royal United Hospital; Mr. L. E. Newman, Royal United Hospital mortuaries, for help in the post-mortemb study; and Mr. J. A. Gray, superintendent radiographer, Royal National Hospital for Rheumatio Diseases, Bath, for help, and Mrs. G. Machinœ medical photographer, Royal United Hospital, Bath:The Arthritis and Rheumatism Council for Research contributed generously to the general expenses of this study. 


\section{References}

Dixon, A. St. J. (1971). The rheumatoid foot. Modern Trends in Rheumatology, Vol. 2, pp. 158-173. Ed. by A. G. S. Hill. Butterworth, London.

Dixon, A. St. J., and Grant, C. (1964). Acute synovial rupture in rheumatoid arthritis. Lancet 1, 742-745.

Dixon, A. St. J., and Rasker, J. J. (1976). Synoviography. Clinics in Rheumatic Diseases, 2, 129-147.

Engelbrecht, E. (1975) Sprunggelenksendo-prosthese Modell "St. Georg". Zeitschrift für Orthopädie, 113, 546-548.

Fulp, M. J. (1973). Arthrography of the ankle. Journal of the American Podiatry Association, 63, 502-511.

Genovese, G. R., Jayson, M. I. V., and Dixon, A. St. J. (1972). Protective value of synovial cysts in rheumatoid knees. Annals of the Rheumatic Diseases, 31, 179-182.

Gerber, N. J., and Dixon, A. St. J. (1974). Synovial cysts and juxta articular bone cysts. Seminars in Arthritis and Rheumatism, 3, 323-347.

Harris, E. J., and Galinski, A. W. (1974). The evaluation of ankle pathology with arthrography. Journal of the American Podiatry Association, 64, 202-215.

Jayson, M. I. V., Cavill, I., and Barks, J. S. (1971). Lymphatic clearance rates in rheumatoid arthritis. Annals of the Rheumatic Diseases, 30, 638-639.

Kalliomaeki, J. L., and Vastamaeki, M. (1968). Chronic diffuse oedema of the rheumatoid hand-a sign of local lymphatic involvement. Annals of the Rheumatic Diseases, 27, 167-169.

Kempson, G. E., Freeman, M. A. R., and Tuke, M. A. (1975). Engineering considerations in the design of an ankle joint. Biomedical Engineering, 10, 166-171 and 180.

Kirkup, J. R. (1974). Ankle and tarsal joints in rheumatoid arthritis. Scandinavian Journal of Rheumatology, 3, 50-52.
Reinhardt, K. (1973). Lymphgefaessdarstellungen bei Obersprunggelenksarthrographien. Radiologie, 13, 451-454.

Ropes, M. W. (1959). Diagnostic criteria for rheumatoid arthritis. 1958 revision. Annals of the Rheumatic Diseases, 18, 49-53.

Sanders, H. W. A. (1973). Arthrography of the ankle joint. Radiologia Clinica et Biologica, 42, 436-437.

Scholz, K. C. (1974). Total ankle replacement arthroplasty. Foot Science, pp. 106-135. Ed. by J. Baleman. Saunders, Philadelphia.

Spiegel, P. K., and Staples, O. S. (1975). Arthrography of the ankle joint: problems in diagnosis of acute lateral ligament injuries. Radiology, 114, 587-590.

Stauffers, R. N. (1976). Total ankle replacement as an alternative to arthrodesis. Geriatrics, 31, 79-85.

Toth, S., Varsanyi, Z., Toth, F., and Gasztonyi, V. (1974). Arthrographie bei Verletzungen im obern Sprunggelenk. Monatsschrift für Unfallheilkunde und Versicherungsmedizin, 77, 545-549.

Vahvanan, V. A. J. (1967). Rheumatoid arthritis in the pantalar joints-a follow up study of triple arthrodesis on 292 adult feet. Acta Orthopaedica Scandinavica, Suppl. 107, 1-157.

Vahvanan, V. A. J. (1968). Synovectomy of the talocrural joint in rheumatoid arthritis. Annales Chirurgicae et Gynaecologicae Fenniae, 57, 576-582.

Vidigal, E., Jacoby, R. J., Dixon, A. St. J., Ratliff, A. H., and Kirkup, J. R. (1975). The foot in rheumatoid arthritis. Annals of the Rheumatic Diseases, 34, 292-297.

Waugh, T. R., Evanski, M. P. and McMaster, W. C. (1976). Irvine ankle arthroplasty. Clinical Orthopaedics, 114, $180-184$. 